\title{
Practical reason in hard times: the effects of economic crisis on the kinds of lives people in the UK have reason to value \\ DOI:
}

10.1080/19452829.2015.1076776

\section{Document Version}

Accepted author manuscript

Link to publication record in Manchester Research Explorer

Citation for published version (APA):

Austin, A. (2015). Practical reason in hard times: the effects of economic crisis on the kinds of lives people in the UK have reason to value. Journal of Human Development and Capabilities, 17(2), 225-244.

https://doi.org/10.1080/19452829.2015.1076776

\section{Published in:}

Journal of Human Development and Capabilities

\section{Citing this paper}

Please note that where the full-text provided on Manchester Research Explorer is the Author Accepted Manuscript or Proof version this may differ from the final Published version. If citing, it is advised that you check and use the publisher's definitive version.

\section{General rights}

Copyright and moral rights for the publications made accessible in the Research Explorer are retained by the authors and/or other copyright owners and it is a condition of accessing publications that users recognise and abide by the legal requirements associated with these rights.

\section{Takedown policy}

If you believe that this document breaches copyright please refer to the University of Manchester's Takedown Procedures [http://man.ac.uk/04Y6Bo] or contact uml.scholarlycommunications@manchester.ac.uk providing relevant details, so we can investigate your claim.

\section{OPEN ACCESS}




\title{
Practical reason in hard times: the effects of economic crisis on the kinds of lives people in the UK have reason to value
}

\begin{abstract}
The capabilities approach was developed partly in response to the problem of adaptive preferences, which is considered by many to be a fatal flaw in utilitarian approaches to well-being. However, an important critique of the capabilities approach is that it is subject to an analogous problem of adaptation to deprivation: if well-being is defined as the capability to live the kind of life one has reason to value, but conceptions of value are conditioned by external circumstances or subject to adaptation, evaluations of well-being in the capability space may suffer similar distortions. This paper investigates the effects of the recent economic crisis in the UK on practical reasoning - on people's conceptions of the good and their freedom to deliberate about the planning of their lives. Using data from the European Social Survey and an Exploratory Structural Equation Modelling approach, it is shown that hard economic times did cause adaptation in conceptions of value, with particularly large effects among the economically vulnerable and the youngest generation. It is concluded that conceptions of value should be included in the definition of capability, and that this strategy can enhance the analytical power of the capabilities approach.
\end{abstract}

Key words: capabilities, well-being, practical reason, adaptation, values

\section{Acknowledgements:}

I am grateful to John O'Neill, Nick Shryane, Hillel Steiner and Stephen Jeffares for their advice and invaluable comments on this work, and thanks to two anonymous reviewers for many suggestions that helped improve the paper. Thanks to colleagues at the Human Welfare Conference 2014 at Templeton Green College, Oxford, and the 2014 Human Development and Capabilities Association conference in Athens, Greece, for useful feedback. Many thanks to David Buckley and the Buckley Scholarship for funding support. 


\section{Introduction}

The capabilities approach was developed partly in response to the problem of adaptive preferences, which is considered by many to be a fatal flaw in utilitarian approaches to well-being:

A person who is ill-fed, undernourished, unsheltered, and ill can still be high up in the scale of happiness or desire fulfilment if he or she has learned to have "realistic" desires and to take pleasures in small mercies. (Sen 1985a)

The phenomenon of adaptation in the context of people's desires, preferences and plans is characterised by Elster (1982) as the "adjustment of people's aspirations to feasible possibilities." In a situation where personal goals do not correspond to the available options, it is often easier to alter the goals than to alter the external situation (Festinger 1954); this may entail a downgrading of the inaccessible options ("sour grapes") or an upgrading of the accessible options (Elster 1982). In a context of adaptation to deprivation, high subjective well-being may simply reflect "cheerful endurance" (Teschl and Comim 2005), the internalization of a disadvantaged position in the social structure, and habituation to unjust and oppressive norms.

Adaptation of this kind can have potentially distorting effects on utility-based evaluations of wellbeing, and it is for this reason that the problem of adaptive preferences is one of the main arguments used to discredit utilitarian approaches to well-being. While the utilitarian account of well-being is grounded in the subjective state of the individual, the capabilities approach (CA) is designed to expand the informational basis of evaluations of well-being beyond the realm of mental states, in order to avoid such distorted results. The CA conceptualises well-being as a function of the individual's opportunity and ability to lead a flourishing human life: in contrast to the monism of utilitarianism, the CA rests on a foundation of value-pluralism, allowing multiple intrinsically valuable ends.

However, a fundamental critique that has been levelled at the CA is that it is subject to an analogous problem, whereby adaptation to deprivation can cause distorted results in capability-based evaluations of the quality of lives (Burchardt 2009; Qizilbash 1997; Teschl and Comim 2005). For example, Qizilbash puts forward a scenario in which a woman and her brother, when assessed at a particular point in time, have equal capability sets; however, in order to achieve equality of capability the woman had to work harder and develop "compensating abilities", due to the poorer life chances she had by virtue of being a woman. In this case, equality of capability is compatible with injustice; for evaluations of well-being in the capabilities space, the problem of compensating abilities represents a type of adjustment to disadvantage that is "closely related to the case of adaptive preferences" (Qizilbash 1997).

A related issue is highlighted by Burchardt (2009), who provides empirical evidence of another kind of response to deprivation: the problem of conditioned expectations. Burchardt shows that individuals' agency goals (their long-term projects, plans and commitments that transcend the meeting of immediate basic needs) are influenced by past experiences of deprivation; in particular, she demonstrates clear socio-economic gradients in young people's educational and occupational 
aspirations, with young people from more disadvantaged backgrounds being less likely to aspire to further education and professional occupations. Interviews with the same sample ten years later, however, showed that those people with more modest aspirations were more likely to achieve their agency goals. Therefore, evaluations of well-being based on agency goal achievement are argued to suffer from a similar distortion to subjective utilitarian evaluations: the conditioning of expectations due to past experience of deprivation and injustice can mask inequalities of freedom, leading to perverse results.

The phenomenon of adaptation to deprivation would seem, then, to pose a problem for the CA: evaluations of well-being grounded in "the kinds of lives people have reason to value" may be problematic, since what people have reason to value may be subject to adaptation and conditioning. This paper re-examines the problem of adaptation and its implications for the CA, focusing on the effects of external circumstances on practical reasoning. In particular, it offers an empirical examination of adaptation in conceptions of value during the recent economic crisis in the UK. Section 1 sets out the theoretical framework of practical reasoning in hard times, and links philosophical conceptions of value with social-psychological theories of personal values. Section 2 uses data from the European Social Survey to investigate the effects of economic crisis on practical reasoning and conceptions of value in the UK. Sections 3 and 4 discuss the implications of the findings for policy and for the CA. The paper concludes by making the case for the inclusion of conceptions of value as part of the definition of capability: although the problem of adaptation to deprivation undermines utilitarian evaluations of well-being, I argue that its incorporation into the definition of capability can increase the analytical power of the CA.

\section{Theoretical framework}

This section introduces the key concepts of practical reason, personal values and adaptation. First, a note on terminology: While Sen distinguishes between the concepts of "well-being" and "agency", I follow Nussbaum in using only the distinction between capability (freedom) and functioning (achievement) (Nussbaum 2000). In what follows, the term "well-being" is used in the Aristotelian sense of eudaimonia, to refer holistically to the realization of human potential through the living of a good, worthwhile life of active being and doing. This includes, by definition, the freedom to exercise agency - to be self-determining, and to reason and develop life-plans and goals.

\section{Practical reason}

At the core of the CA is people's opportunity and ability to live flourishing human lives (Sen 1999), with practical reason central to the development of personal conceptions of what constitutes a good life (Nussbaum 2000). Aristotle defined the process of practical reasoning as:

To deliberate rightly about what is good and advantageous to [oneself]; not in particular respects, e.g. what is good for health or physical strength, but what is conducive to the good life generally. (EN6 1140a26-29) 
Accordingly, Nussbaum's (2000) definition of the capability for practical reason is "Being able to form a conception of the good and to engage in critical reflection about the planning of one's life." Within her list of core capabilities, Nussbaum places special importance on practical reason, since, along with the capability for affiliation, it "organize[s] and suffuse[s] all the others."

Different accounts of practical reason exist; the view closest to Aristotle's definition (Wiggins 2001) is the specificationist account. This theory of practical reason holds that many of our ends are defined only abstractly and imprecisely; practical reasoning involves the more detailed specification of these indefinite, incomplete goals, and the creation of consistency between different (often conflicting) ends, in the context of real-life circumstances (Wiggins 2001). An important feature of the specificationist account, therefore, is that it provides the basis of a dynamic view of conceptions of the good, whereby what people consider as conducive to a good life is subject to modification in response to changing circumstances. A person's conception of the good life is fundamental to how her life goes - it determines the parameters of her expectations, aspirations and life goals, the locus of possibility that she can imagine for herself, and the broadness or narrowness of her horizons. Changes in conceptions of the good entail the modification of ends, and of the plans and aspirations that people develop to achieve those goals: conceptions of the good and changes therein govern the shape of people's lives and, therefore, their freedom to flourish.

The specificationist account of practical reason is complemented well by various social-psychological theories of personal values - the next section highlights the theoretical connection between practical reasoning and personal values; in particular, I aim to show that an individual's personal values are an expression of her conception of the good.

\section{Practical reason and personal values}

The Social-Psychology literature contains myriad definitions of personal values (hereafter "values"), including Allport's (1961) simple statement that values are "basic convictions about what is and is not important in life," and Kluckhohn's (1951) definition of values as "a conception...of the desirable." Values are enduring beliefs about personally or socially desirable modes of behaviour and end-states of existence (Rokeach 1973; note the parallel with Sen's 'doings' and 'beings'), that are the result of specific intersections of cultural and social learning (socialisation), an individual's location in the social structure, and personal experience (Schwartz 1992). Values are central to an individual's selfconcept (Hitlin and Piliavin 2004; Rohan 2000); they are commitments to living a certain kind of life and being a certain type of person, that become an embodied part of individual identity (Sayer 2011). The role of personal values in self-identity provides a direct link to the theory of practical reason, which also involves the building and maintenance of a coherent self-concept or "practical identity" (Korsgaard 2009).

Values focus on ideals, rather than concrete social objects (Clawson and Vinson 1978), and one of their main functions is to provide standards or criteria that people use to plan, select and justify actions, and to evaluate situations, objects, others, and the self (Rohan 2000); they are heuristic summaries of past experiences that serve as "latent guides for evaluations of the social world" (Hitlin and Piliavin 2004). This focus on ideals - the prioritisation of certain ways of being and doing 
over and above alternatives - provides a further connection between personal values and practical reason. Values are often conceptualised as tools that ultimately serve a higher end, with that higher end defined as "well-being" (Camfield, Choudhury and Devine 2009) or "self-actualization" (Maslow 1943). This illuminates the link between the Aristotelian account of well-being at the heart of the CA, and the social-psychological concept of personal values: values are an expression of idealised beings and doings; they embody the basic structure and character of a person's conception of the good life, and are a summary of the kind of life she has found reason to value.

Finally, social-psychological theories also recognise a central issue related to value-pluralism. There is a plurality of human values, and in any given situation, multiple values may be activated and may conflict; values must therefore be rank ordered via "priority rules" (Steiner 1994) in order to provide a consistent guide to making evaluations and resolving conflicts. These different prioritisations are defined by social psychologists as value systems or "value orientations" (Rokeach 1973). For the purposes of the current analysis, these underlying orderings will be interpreted as summary representations of conceptions of the good life.

Combining the specificationist account of practical reason with social-psychological theories of personal values leads to the following schema: the ultimate final end for all individuals is eudaimonia (the living of a good, worthwhile life of valuable being and doing); personal values are expressions of the abstract, incomplete goals that constitute the substantive content of the individual's conception of the good life; and life plans and aspirations are the more detailed specifications of how people intend to realize those goals. Practical reasoning works to maintain coherence between the abstract conception of value and the concrete specified plans, in the social-political-material context within which people find themselves.

\section{Adaptation: identifying "downgrades"}

The preceding discussion has established the theoretical link between practical reason and personal values, and provided the basis for a dynamic view of conceptions of value and their associated plans and aspirations. Of particular interest for the current analysis is the modification of values that amounts to a "downgrading" of goals; however, adaptation can take many forms, and the term "adaptation" is best viewed as a "collective noun" (Teschl and Comim 2005) that refers to various different types of process, not all of which are inherently negative. For example, "flexible goal adjustment" is acknowledged to have positive effects on the subjective happiness of elderly people (Brandtstadter and Renner 1990), and Nussbaum (2000:137) comments that "...even if, as children, we wanted to fly like birds, we simply drop that after a while, and are probably the better for it." Despite adaptive preferences being problematic in subjective evaluations of well-being, it is therefore not the case that all adaptation necessarily entails some form of downgrading. The final link between adaptive conceptions of value and well-being is the need to differentiate between beneficial adaptation and adaptation that causes harm to a person's capability to flourish.

In their Theory of Human Need (THN), Doyal and Gough (1991) propose a structure of hierarchical relationships between different levels of need. They define certain features of individual and social life as essential for the ultimate goal of "social participation in one's chosen form of life", with 
minimum levels of basic needs such as physical and economic security required as a foundation for striving towards higher goals. The idea of a hierarchy of needs is also found in the social psychology literature: for example, Maslow's (1943) Theory of Human Motivation differentiates between "deficiency" goals, which are rooted in the need to meet basic survival needs, and "self-actualization" goals, rooted in "higher" needs and commitments beyond basic survival, such as personal and social achievement, creativity and self-confidence; these values correspond to what Sen (1985b) calls agency goals. According to the theory, deficiency needs must be met before higher goals can be pursued. At both the group and individual levels, increases in material prosperity are associated with a shift away from deficiency values (Inglehart 1977; Maslow 1943): once basic needs are met, people are free to address higher goals.

The social-psychological theories and the THN both exemplify the idea that values and needs can be classified as 'basic' and 'higher'. This is a common view in moral and political philosophy, perhaps most clearly exemplified in Mill's distinction between higher and lower pleasures (Mill 1998/1871). The central idea that goals and needs can be independently categorised as more or less valuable in terms of well-being fits well with the $\mathrm{CA}$, and with an Aristotelian account of well-being more generally. Doyal and Gough's highest goal is "social participation in [one's] chosen form of life", and Maslow's ultimate value of "self-actualization" is specified as "doing what one is fitted for" and "becoming all that one is capable of becoming" (Maslow 1943:382); both are very close to the Aristotelian concept of eudaimonia.

In the language of capabilities, movement away from basic needs towards higher goals entails a broadening of the opportunities (the set of feasible functioning vectors) from which people can choose - an expansion of capabilities. Any reversal of this - a descent downwards in the hierarchy of needs towards deficiency values - would represent a move away from higher goals, and a diminishment of capability: conceptions of value that do not extend beyond concern for basic material security needs stifle human agency and can crowd out self-actualizing agency goals.

The empirical part (Section 2) of this paper will use a modified version of the hierarchy of needs, and classify conceptions of the good as prioritising either 'Subsistence' or 'Human Potential' goals. Subsistence goals relate to basic or deficiency needs, while Human Potential goals are the higher agency goals toward which people strive and that make life meaningful and worthwhile. This classification will be used in Section 2 to identify when adaptation in conceptions of value represents a 'downgrade' in goals.

\section{Practical reasoning and internal capabilities}

The idea of practical reasoning is central to Nussbaum's neo-Aristotelian formulation of the CA. Nussbaum (2000) distinguishes between different dimensions of capability: on this account, basic capabilities are the "innate equipment" of human beings (for example the innate capability for language); internal capabilities are "developed states of the person" that are required for the exercise of a functioning; and combined capabilities reflect the combination of internal capabilities with external conditions that enable (or at least do not block) functioning. For example, political participation is a combined capability - it requires both the internal capability of the individual to 
form opinions and engage with issues, as well as political freedom and opportunities to participate. On this basis, an individual's mode of practical reasoning may be defined as part of her internal capability. Different modes of practical reasoning are associated with different degrees of autonomy of agency: practical reasoning characterised by a focus on subsistence goals represents constrained agency and narrower horizons of aspiration; this constitutes a constraint on internal (and therefore combined) capability.

\section{The kinds of lives people 'have reason to value'}

The conceptual considerations set out above come together in the idea of people having freedom to live 'the kinds of lives they have reason to value.' Sen (1985a) makes the distinction between what people have their own subjective reasons to value, and what they have reason to value from an objective point of view. The difference between these two types of 'reason' is captured in the distinction between 'motivating' and 'normative' reasons. Motivating reasons are the individual's own personal reasons that she would cite when explaining her decisions and actions; these types of reasons are "complexes of beliefs and desires that motivate action" (Smith 1994). Motivating reasons are distinct from 'normative reasons', which refer to "facts about the world" or states of affairs that provide independent justification for a person's decisions and actions (Smith 1994). While motivating reasons are features of an agent's psychology, normative reasons are not. For example, there may be good (normative) reason for a person to do pilates to help her back problem, but she doesn't know this and in any case she dislikes exercise - she has no motivating reasons to sign up for a class. This demonstrates that motivating and normative reasons are not necessarily the same, although they can be: if I have a true belief that the volcano will erupt tonight, this is both a motivating and normative reason to evacuate my house on the slopes of the volcano. For Dancy (2000), an individual whose motivating reasons are identical with normative reasons is 'in sound normative form'.

Given the problem of adaptive preferences, it would seem that Sen is primarily interested in the normative reading of 'having reason to value' - that is, he is postulating the existence of some objective 'facts about the world' relating to well-being. This would be in line with Aristotle, who clearly refers to the existence of some objective truth about well-being in his statement about deliberating "rightly" about the good life (EN6 1140a26-29). However, sometimes Sen's position is unclear. For example, he refers to a person's freedom to "get systematically what he would choose", and to "Being able to live as one would value, desire and choose...(and would have reasons to choose)" (Sen 1992). The direct reference to agents' personal choices relates to motivating reasons, rather than to a non-psychological objective fact about the world (a normative reason). Sen also puts particular emphasis on "reasoned evaluation" and "reflection" (Sen 1999), which again suggests that motivating reasons (developed through practical reasoning) are what is referred to in the phrase 'have reason to value', and links directly to the idea of personal values as 'reasoned metapreferences' (see above).

The tension between what people have motivating reasons to value and what there is normative reason to value is the basis of the paternalism objection that is often mounted against the CA. However, the failure of utilitarian accounts of well-being to recognise the distinction leaves them open to charges of relativism and to the problem of adaptive preferences, since all preferences, 
including those developed in circumstances of injustice and oppression, enter into the equation. As a neo-Aristotelian theory, the CA addresses this tension by defining well-being in terms of individual freedom (based on the assumption of normative individualism), in combination with background social and political conditions that are just and that enable practical reasoning in accordance with what there is normative reason to value, with this defined through processes of philosophical reasoning and/or public participation and deliberation.

To clarify this area of ambiguity, the following definitions and terminology will be used in this paper: first, value orientations are defined as summary representations of what people have found motivating reasons to value through their own processes of reasoned evaluation and reflection; second, the Subsistence/Human Potential classification system (see above) will be used as an independent grounding for the identification of downgrades in goals and aspirations on the basis of what there is normative reason to value with reference to well-being and flourishing.

\section{Hard times and adaptation in the UK}

In the analyses below, personal values theory is used alongside the CA and the theory of practical reason to set up and test hypotheses about the impact of economic crisis in the UK on practical reasoning. It is hypothesised that economic hard times do have an effect on conceptions of value, and that the effect amounts to a downgrading of goals and aspirations. Furthermore, it is expected that this adaptation will be unequally distributed in the population. The hypotheses are set out in detail and tested in section 2.2; the first step in the analysis is the development of a measurement model of conceptions of the good.

\subsection{Analysis: Measuring conceptions of the good}

Aristotle pointed out that there is a plurality of views as to what constitutes a good life, and "It would no doubt be rather futile to examine all these [views]; enough if we consider those which are most prevalent..." (EN1iv1095a28-30). In order to operationalize the idea of conceptions of the good, I use a latent variable approach (factor analysis) to identify underlying dimensions in data from the European Social Survey on value priorities in the UK. Factor analysis is a method of investigating patterns of variation in data, through an exploration of the associations between the observed variables of interest (in this case, survey questions about personal values), and a hypothesised set of unobserved, latent dimensions (here, value orientations). This method is an ideal strategy for developing a measurement model of conceptions of the good: first, it accords with the theoretical status of value orientations as latent constructs that underpin specific evaluations about the world; second, it captures the idea of differential weights or orderings being given to values; and third, it functions as a data reduction technique, enabling discovery of the conceptions of the good that are, broadly speaking, "most prevalent."

\section{Data and methods}

The European Social Survey (ESS) is a bi-annual repeated cross-sectional survey conducted in up to 32 European countries. The dataset used here comprises a bi-annual probability sample of UK residents aged 15 years or over living in private households. It is important to note that the crosssectional design of the survey means that the analysis cannot directly identify causal processes in 
changes in conceptions of the good; longitudinal analysis would be required to establish causality and identify trajectories of individual-level adaptation. However, due to the absence of suitable longitudinal data on value priorities in the UK, the analysis instead compares 'equivalent' groups across time periods with cross-sectional data.

The ESS measures personal value priorities using the framework provided by Schwartz's (1992) Theory of Human Values, which postulates a set of core values which are universally recognised, but differentially prioritised. The theory provides an eight-value typology for the UK (Davidov, Schmidt and Schwartz 2008):

- Benevolence - Preservation and enhancement of the welfare of people with whom one is in frequent personal contact

- Universalism - Understanding, appreciation, tolerance and protection for the welfare of all people and for nature

- Self-Direction - Independent thought and action-choosing, creating, exploring

- Stimulation - Excitement, novelty, and challenge in life

- Hedonism - Pleasure and sensuous gratification for oneself

- Power-Achievement - Social status and prestige, control or dominance over people and resources; personal success through demonstrating competence according to social standards

- Conformity-Tradition - Restraint of actions, inclinations, and impulses likely to upset or harm others and violate social expectations or norms; respect, commitment and acceptance of the customs and ideas that traditional culture or religion provide the self

- Security - Safety, harmony, stability of society, of relationships, and of self

The ESS uses a 21-item instrument designed to measure the eight core values, known as the Portrait Values Questionnaire (Schwartz 2003). Respondents are asked about their level of identification with 21 pen-portraits of different types of person (matched to the gender of the respondent), rating each along a six-point scale from "Very much like me" to "Not like me at all". Individual scores for the eight core values consist of the mean score of the individual items designed to measure each value. ${ }^{1}$ For example, the following portraits describe people for whom Self-Direction and Tradition values, respectively, are important:

Thinking up new ideas and being creative is important to her. She likes to do things in her own original way.

He thinks it is important not to ask for more than what you have. He believes that people should be satisfied with what they have. (European Social Survey 2014)

The first stage of the analysis used pooled data on personal values from the first five rounds of the ESS (2002-2010). An Exploratory Factor Analysis (EFA) was performed as a means of distilling the sets 
of priorities representing the most common conceptions of the good in the UK in the first decade of the $21^{\text {st }}$ century. Table 1 shows the results.

\begin{tabular}{|c|c|c|c|}
\hline Model fit statistics: & F1 & F2 & F3 \\
\hline $\begin{array}{l}\text { TLI: } 0.97 \\
\text { CFI: } 0.99 \\
\text { SRMR: } 0.01\end{array}$ & Carpe Diem & Security-Conformity & Pro-social \\
\hline Benevolence & 0.07 & 0.21 & 0.35 \\
\hline Universalism & -0.03 & 0.06 & 0.59 \\
\hline Self-direction & 0.34 & -0.05 & 0.35 \\
\hline Stimulation & 0.91 & -0.20 & 0.20 \\
\hline Hedonism & 0.82 & 0.11 & -0.05 \\
\hline Power-Achievement & 0.62 & 0.29 & -0.09 \\
\hline Conformity-Tradition & -0.08 & 0.58 & 0.16 \\
\hline Security & 0.06 & 0.68 & 0.05 \\
\hline Factor correlations & \multicolumn{3}{|c|}{ Factor Descriptions (value priorities) } \\
\hline $\begin{array}{l}\text { F1 (Carpe Diem) with } \\
\text { F2 (Security-Conformity): } \\
\text { r=0.11 } \\
\text { F1 (Carpe Diem) with } \\
\text { F3 (Pro-social): } \\
\text { r=0.22 } \\
\text { F2 (Security-Conformity) with } \\
\text { F3 (Pro-social): } \\
\text { r=0.34 }\end{array}$ & $\begin{array}{l}\text { STIMULATION: } \\
\text { Excitement, novelty, and } \\
\text { challenge in life } \\
\text { HEDONISM: Pleasure } \\
\text { and sensuous } \\
\text { gratification for oneself } \\
\text { POWER: Social status } \\
\text { and prestige, control or } \\
\text { dominance over people } \\
\text { and resources } \\
\text { ACHIEVEMENT: Personal } \\
\text { success through } \\
\text { demonstrating } \\
\text { competence according to } \\
\text { social standards }\end{array}$ & $\begin{array}{l}\text { CONFORMITY: Restraint } \\
\text { of actions, inclinations, } \\
\text { and impulses likely to } \\
\text { upset or harm others } \\
\text { and violate social } \\
\text { expectations or norms } \\
\text { TRADITION: Respect, } \\
\text { commitment and } \\
\text { acceptance of the } \\
\text { customs and ideas that } \\
\text { traditional culture or } \\
\text { religion provide the self } \\
\text { SECURITY: Safety, } \\
\text { harmony and stability of } \\
\text { society, of relationships, } \\
\text { and of self }\end{array}$ & $\begin{array}{l}\text { BENEVOLENCE: } \\
\text { Preservation and } \\
\text { enhancement of the } \\
\text { welfare of people with } \\
\text { whom one is in frequent } \\
\text { personal contact } \\
\text { UNIVERSALISM: } \\
\text { Understanding, } \\
\text { appreciation, tolerance } \\
\text { and protection for the } \\
\text { welfare of all people and } \\
\text { for nature } \\
\text { SELF-DIRECTION: } \\
\text { Independent thought } \\
\text { and action-choosing, } \\
\text { creating, exploring }\end{array}$ \\
\hline $\begin{array}{l}\text { Notes } \\
\text { Factors rotated using Geomin } \\
\text { Factor loadings } \geq 0.4 \text { (to } 1 \text { dec } \\
\text { Standardized loadings }\end{array}$ & $\begin{array}{l}\text { tation (oblique rotation, al } \\
\text { lal place) highlighted }\end{array}$ & wing correlated factors) & \\
\hline
\end{tabular}

Three dimensions emerge as the most prevalent value orientations. It is important to note that, according to theories of personal values, all the basic values are universally recognised, but people are differentiated in the priority-rules that they assign to them. Therefore, both theoretically and empirically speaking, all factors are expected to be present in all cases (i.e. individuals); however, every individual is expected to identify most strongly with (score highest on) one dominant factor. This dominant factor is interpreted as their value orientation, a summary of their personal conception of the good. 
The three factors are labelled (1) Carpe Diem, (2) Security-Conformity and (3) Pro-Social. The factor labelled Carpe Diem (in Latin, "Seize the day") represents a somewhat self-focused value orientation: priority is given to personal (perhaps individualistic) goals such as personal achievement, having a good time, seeking adventure and taking risks. In contrast, people with a high score on the Pro-Social value orientation are particularly other-focused: their top priorities in life are the welfare not only of their close family and friends, but of all people, and they are concerned with justice, equality and the environment.

Of most relevance to the current analysis, however, is Factor 2 (Security-Conformity). It is striking that this value orientation is defined principally by the central goal of conserving the stability of the self and the social group. This factor is dominated by the Conformity-Tradition and Security values, with negative loadings (representing rejection) on Self-Direction and Stimulation. People who score high on this factor consider stability, certainty and adherence to social norms to be very important, and may be thought of as somewhat risk-averse: excitement, novelty and challenge are not guiding principles, and the goals of creativity and originality are de-prioritised. Value priorities like these are often interpreted as a response to material uncertainty, instability and "existential threat" (Inglehart 1977; Schwartz 1992), and correspond closely to subsistence goals, which dominate when basic needs are unmet or threatened. The factor correlations confirm that the weakest relationship exists between the Security-Conformity and Carpe Diem orientations, due to the incompatibility of, on one hand, inward-facing subsistence goals and, on the other, the wide horizons of ambition and adventure associated with Carpe Diem priorities.

With the measurement model in place, the next section sets out and tests specific hypotheses about the effects of hard times on practical reasoning.

\subsection{Analysis: The effects of hard times on conceptions of the good}

It was established in Section 1 that, through processes of practical reasoning, changes in the material context within which people live would be expected to cause adaptation in the kinds of goals that they prioritise, and therefore in the plans that they specify in order to achieve those goals. Personal values theory enables adaptation to be characterised as a shift toward or away from the fulfilment of human potential: an increase in the importance of subsistence values would reflect a shift downwards in the hierarchy of needs, and a downgrading of goals. In a context of material hardship and uncertainty, it is expected that people would become more concerned about, and increase the value they place on, Security-Conformity goals such as stability, safety and certainty. The analysis below examines specific questions about whether, how, and for whom, hard times influence the evolution of conceptions of the good and the (re-) specification of ends.

The first hypothesis takes a broad view on the UK population as a whole:

\section{H1: Hard times will lead to changes in the kinds of lives people in the UK have reason to value} H1a: The importance of subsistence values will increase during Hard Times 
The second and third hypotheses relate to where in society the effects of hard times are most keenly felt. It is expected that downward adaptation will take place particularly among economically vulnerable groups, since these groups have fewest resources - including both economic and human capital - to cope with hardship. Although adaptation is a standard part of human life, the reasons that motivate adaptation are important both morally and for policy: high levels of adaptation among particular groups would indicate underlying inequality and injustice.

H2: Increases in the importance of subsistence values will be concentrated among economically vulnerable groups

Finally, based on Mannheim's theory of generations (Mannheim 1952), it is expected that hard times will have a particularly strong effect on those in their formative years. According to this theory, value orientations are established through processes of socialisation, and early adulthood is an important life-stage in the setting of future trajectories. Furthermore, Mannheim's theory postulates that social change occurs through a process of generational replacement, whereby successive cohorts, socialised within specific configurations of social-economic-political conditions, bring their own value priorities into public life when they come of age. As such, the conditioning of the goals and expectations of this cohort would be expected not only to influence the future well-being of those individuals, but also to have wider implications for society more generally.

\section{H3: There will be increased prioritisation of subsistence values among the formative} generation during Hard Times

\section{Method and variables}

The analysis employs structural equation modelling techniques, which is a family of methods that is increasingly used in a capabilities context (e.g. Anand, Krishnakumar and Tran 2011; Krishnakumar and Ballon 2008; Kuklys 2005). An Exploratory Structural Equation Modelling (ESEM) approach (Asparouhov and Muthen 2009) is used to extend the EFA measurement model of conceptions of the good. All analyses were carried out using MPlus7 software.

First, pooled data from all five rounds of the ESS is used in order to investigate the effect of hard times as a macro-economic phenomenon affecting everyone, regardless of location in the social structure - in statistical terms this is known as a Period Effect. Second, a multiple-group approach is taken in order to focus on differences over time. The dataset is split into two groups: Group 1 is labelled Times of Plenty, and comprises data from rounds 1-3 of the survey (2002-2006); group 2 is labelled Hard Times, and is made up of data from rounds 4-5 (2008-2010). This definition of Hard Times is based on macro-economic data: over the five year period 2008-2012, the UK economy shrank by an annual average of $-0.6 \%$ (-5.2\% in 2009), compared to an average of $3.3 \%$ annual growth over the five years of 2003-2007 (World Bank 2013). Although the UK economy began a slow recovery in 2010, the lagged effects of the recession on the economy and the labour market continued to affect people's lives long after GDP turned positive (e.g. ONS 2012), as did the political climate of austerity (e.g. Slay and Penny 2013). The logic of the multiple-group approach is that the 
entire model is interacted with the groups - in this case, time periods - so that comparisons can be made. ${ }^{2}$ Wald tests are used to test differences across time periods.

The first part of the analysis below focuses on the period effects of economic crisis on conceptions of the good. The analysis includes both period and cohort effects: Period is represented in the model by a dummy variable that compares the period of Hard Times to the preceding Times of Plenty. Cohort categories are constructed roughly according to commonly accepted definitions (Ipsos-Mori 2012); only the usual Generation $Y$ (1980-1990) is split into two categories - Generation Y1 (GenY1, born 1980-85) and Generation Hard Times (GenHT, born 1986-1990). The purpose of this is to allow further analysis of the cohort in their formative years (aged 16-24) during Hard Times. In order to minimise confounding between period and cohort effects, the very oldest members of the Times of Plenty group and the very youngest members of the Hard Times group were removed; the final sample is therefore restricted to those born between 1912-1990 (inclusive), so that each group in the multiple-group analysis contains identical birth cohorts.

Basic socio-demographic and economic characteristics (gender, labour market status, income and education) are also controlled, given that values are partly a function of one's location in the social structure (Rokeach 1973). Some of the socio-demographic variables also control indirectly for age, since they are "lifecycle characteristic" variables that represent life-stage (being a student or being retired, marital status and having children living at home). ${ }^{3}$

The last two sets of variables contain the main indicators of economic vulnerability, including employment status, household income and level of education. ${ }^{4}$ In all cases, the reference category is the more advantaged section of society, since the focus here is on the most vulnerable. The Lowincome variable flags households at or below the UK government threshold for relative poverty (DWP 2013), i.e. an annual income less than $60 \%$ of the contemporary national median income. The Medium-low category includes households below the median, but outside of the official low-income category; the reference category is therefore those living in households above the median income. ${ }^{5}$

\subsection{Results}

Table 2 shows the results of an exploratory factor analysis with covariates, conducted within the ESEM framework. This analysis was designed to test Hypotheses 1 and $1 \mathrm{a}$, relating to the effects of hard times on the population as a whole:

\section{H1: Hard times will lead to changes in the kinds of lives people in the UK have reason to value} H1a: The importance of subsistence values will increase during Hard Times 


\begin{tabular}{|c|c|c|c|c|c|c|c|}
\hline & \multirow{3}{*}{$\begin{array}{ll}\text { Model fit statistics: } & \text { RMSEA: } 0.04 \\
& \text { CFI: } 0.93 \\
& \text { TLI: } 0.87 \\
& \text { SRMR: } 0.02\end{array}$} & \multirow{2}{*}{\multicolumn{2}{|c|}{$\frac{1}{\text { Carpe Diem }}$}} & \multicolumn{2}{|c|}{2} & \multicolumn{2}{|c|}{3} \\
\hline & & & & \multicolumn{2}{|c|}{ Security-Conformity } & \multicolumn{2}{|c|}{ Pro-social } \\
\hline & & $\beta$ & (p) & $\beta$ & (p) & $\beta$ & (p) \\
\hline \multirow[t]{2}{*}{1} & $\begin{array}{l}\text { Period of Hard Times } \\
\text { (2008-2010; ref category 2002-2006) }\end{array}$ & -0.14 & $(0.00)$ & 0.14 & $(0.00)$ & 0.10 & $(0.00)$ \\
\hline & \multicolumn{7}{|l|}{ Cohort (ref category Traditionalists, pre-1945) } \\
\hline 2 & $\begin{array}{l}\text { Babyboomers (1945-1960) } \\
\text { Generation X (1961-1979) } \\
\text { Generation Y1 (1980-1985) } \\
\text { Generation Hard Times (1986-1990) }\end{array}$ & $\begin{array}{l}0.23 \\
0.62 \\
1.16 \\
1.39\end{array}$ & $\begin{array}{l}(0.00) \\
(0.00) \\
(0.00) \\
(0.00)\end{array}$ & $\begin{array}{r}-0.19 \\
-0.20 \\
-0.16 \\
-0.28\end{array}$ & $\begin{array}{l}(0.00) \\
(0.00) \\
(0.03) \\
(0.00)\end{array}$ & $\begin{array}{r}0.11 \\
0.03 \\
-0.01 \\
-0.30\end{array}$ & $\begin{array}{l}\mathbf{( 0 . 0 5 )} \\
(0.68) \\
(0.94) \\
(0.00)\end{array}$ \\
\hline & \multicolumn{7}{|c|}{ Socio-demographic characteristics (ref categories: male, single, no children at home) } \\
\hline \multirow[t]{2}{*}{3} & $\begin{array}{l}\text { Female } \\
\text { Married/lives with partner } \\
\text { Children living at home }\end{array}$ & $\begin{array}{l}-0.29 \\
-0.12 \\
-0.16\end{array}$ & $\begin{array}{l}(0.00) \\
(0.00) \\
(0.00)\end{array}$ & $\begin{array}{l}0.01 \\
0.13 \\
0.03\end{array}$ & $\begin{array}{l}(0.71) \\
(0.00) \\
(0.40)\end{array}$ & $\begin{array}{l}0.15 \\
-0.07 \\
-0.10\end{array}$ & $\begin{array}{l}(0.00) \\
(0.02) \\
(0.00)\end{array}$ \\
\hline & \multicolumn{7}{|c|}{ Labour market status (ref categories: paid work/housework) } \\
\hline 4 & $\begin{array}{l}\text { Currently unemployed } \\
\text { Permanently sick or disabled } \\
\text { In education } \\
\text { Retired }\end{array}$ & $\begin{array}{r}0.14 \\
-0.22 \\
0.11 \\
-0.22\end{array}$ & $\begin{array}{l}(0.02) \\
(0.00) \\
(0.10) \\
(0.00)\end{array}$ & $\begin{array}{r}-0.14 \\
0.00 \\
-0.12 \\
0.09\end{array}$ & $\begin{array}{l}(0.04) \\
(0.95) \\
(0.15) \\
(0.10)\end{array}$ & $\begin{array}{l}0.10 \\
0.17 \\
0.29 \\
0.14\end{array}$ & $\begin{array}{l}(0.14) \\
(0.01) \\
(0.00) \\
(0.01)\end{array}$ \\
\hline & \multicolumn{7}{|c|}{ Income and education (ref categories: above median income; higher education) } \\
\hline \multirow[t]{3}{*}{5} & $\begin{array}{l}\text { Low income (<60\% median) } \\
\text { Medium-low income } \\
\text { Education: No qualifications } \\
\text { Education: GCSEs }\end{array}$ & $\begin{array}{l}-0.21 \\
-0.12 \\
-0.10 \\
-0.09\end{array}$ & $\begin{array}{l}(0.00) \\
(0.00) \\
(0.01) \\
(0.01)\end{array}$ & $\begin{array}{l}0.19 \\
0.07 \\
0.30 \\
0.08\end{array}$ & $\begin{array}{l}(0.00) \\
(0.06) \\
(0.00) \\
(0.04)\end{array}$ & $\begin{array}{r}0.13 \\
0.05 \\
-0.29 \\
-0.34\end{array}$ & $\begin{array}{l}(0.00) \\
(0.22) \\
(0.00) \\
(0.00)\end{array}$ \\
\hline & $\mathbf{R}^{2}$ & \multicolumn{2}{|c|}{0.26} & \multicolumn{2}{|c|}{0.07} & \multicolumn{2}{|c|}{0.05} \\
\hline & \multicolumn{7}{|c|}{$\begin{array}{l}\text { Notes } \\
\text { Figures in bold are statistically significant at } p \leq 0.05 \\
\text { Good model fit is indicated by: RMSEA } \leq 0.05 ; T L I, C F I \geq 0.90 ; \text { SRMR } \leq 0.08 \text { (Marsh et al. 2011). } \\
\text { Cohorts restricted to } 1912-1990 \text { (inclusive), } n=8,567 \\
\text { Standardized coefficients }\end{array}$} \\
\hline
\end{tabular}

The results provide support for $\mathrm{H} 1$ and $\mathrm{H} 1 \mathrm{a}$ : Row 1 shows a statistically significant period effect for all three value orientations, indicating shifts in conceptions of value across the two time periods. Most importantly for the current analysis, the effect for Security-Conformity values is positive, showing that subsistence values increased in importance during hard times.

The table also provides insight into the cross-sectional distribution of the value orientations. For example, low economic status in terms of low income and low educational qualifications was, on average, associated with prioritisation of subsistence values (Row 5). ${ }^{6}$ There is also evidence of a cohort effect for subsistence values (Row 2): there is a broadly negative generational change, with successive cohorts valuing Security-Conformity less than the previous generation, and the youngest cohort valuing them least of all. 


\section{Economic vulnerability and young people}

The final part of the analysis used a multiple-group approach to test predictions about which groups would re-specify their goals in accordance with subsistence needs:

H2: Increases in the importance of subsistence values will be concentrated among economically vulnerable groups

H3: There will be increased prioritisation of subsistence values among the formative generation during Hard Times

Table 3 shows the results.

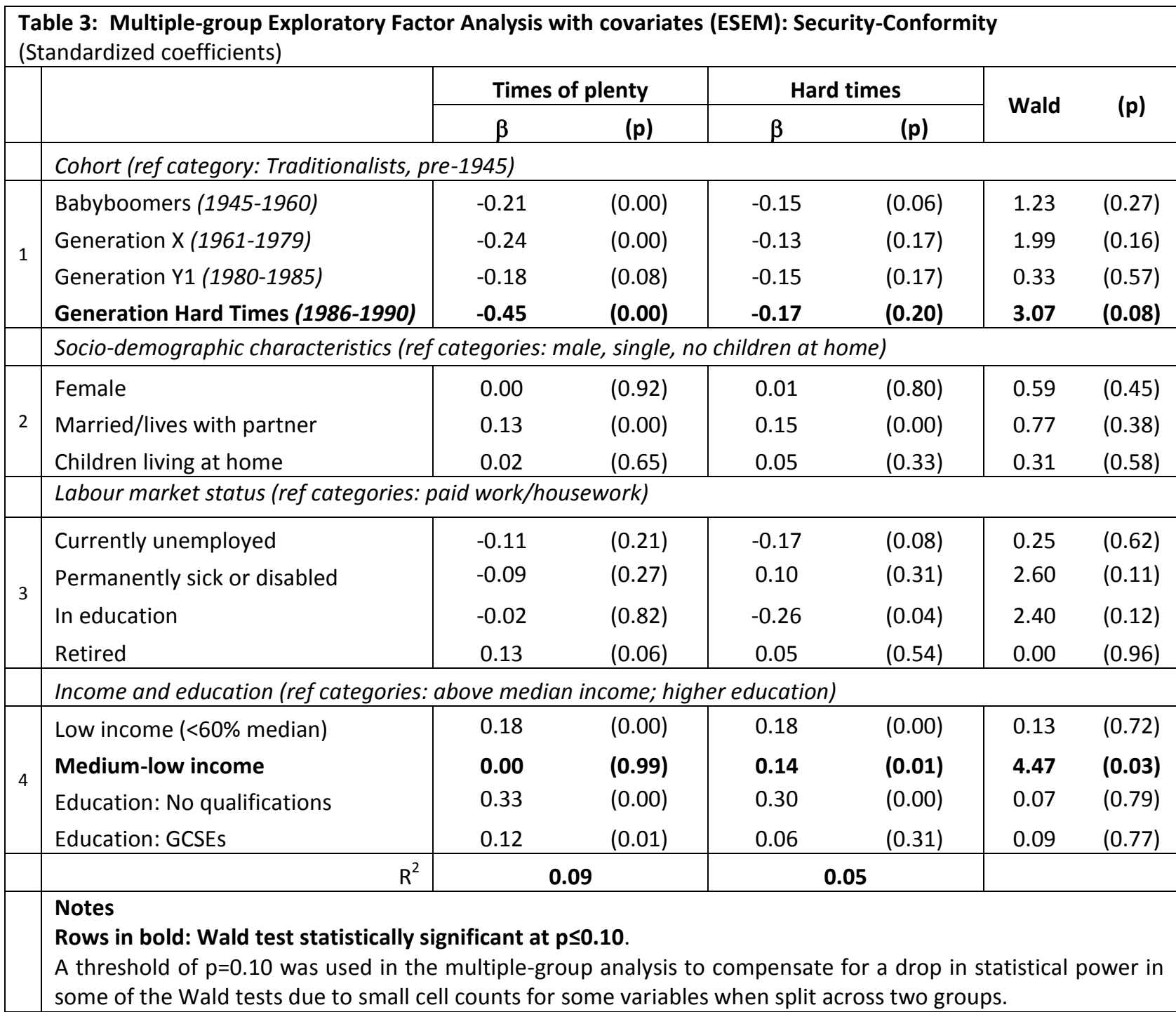

The results provide broad support for hypotheses $\mathrm{H} 2$ and H3: Row 4 confirms that having a household income below the median was associated with a statistically significant increase in the 
importance of subsistence values in hard times; and Row 1 shows that those in the formative generation during hard times prioritised subsistence values significantly more than their predecessor formative cohort during times of plenty.

\section{Discussion}

Two main discussion points emerge from the analysis: first, the effects of economic crisis on practical reasoning in the UK, ${ }^{7}$ and second, the implications of the findings for the CA.

\section{Hard times and practical reasoning}

This analysis has shown that hard economic times did influence practical reasoning: during the economic crisis of the late 2000s, there was social change in the UK whereby society as a whole, on average, placed increased importance on subsistence values such as safety, stability and certainty. This change was in the opposite direction to the underlying long-range cohort trend in the UK of decreasing prioritisation of Security-Conformity values.

It is only once basic needs are met that people are free to address higher human potential goals (Doyal and Gough 1991; Maslow 1943; Sen 1999); the increased prioritisation of goals relating to subsistence needs implies a reduced focus on agency goals - a narrowing of horizons and a downgrading of ambitions and aspirations, amounting to a diminishment of internal capability. This downgrade constitutes a subjective constraint on capability, just as material hardship represents an objective constraint. Combined capabilities reflect "the complex inter-relationship between human striving and its social and material context" (Nussbaum 2000); they are the result of the dynamic interaction between internal capabilities and external circumstances. The results therefore show that economic crisis had a two-fold effect, with detrimental impacts on both the objective/external and subjective/internal dimensions of combined capabilities.

The findings also show that adaptation at the average population level was not evenly distributed. Analysis of the interaction of micro-level (individual and household) economic vulnerability and macro-level national hard times showed that adaptation was particularly strong among those of lower economic status, confirming that certain sections of society are more exposed to changes in external circumstances. The association between low income and Security-Conformity values became stronger in hard times, except among the very poorest: those on the lowest incomes prioritised subsistence values highly in both time periods, while those in the second income category (below the median but above the government poverty threshold) placed significantly more importance on Security-Conformity values in hard times. This finding suggests that there may be a 'floor effect' in the relationship between low income and subsistence values, implying that the deprivation of the poorest households is deeply entrenched, and that poverty is a constant reality for some households, regardless of macro-economic cycles of boom and bust. This accords with findings in a paper entitled "Recession, it's all the same to us son" (Emmel and Hughes 2010), which reported that the recession was "barely noticed" among "core poor households", whose experience of deprivation is affected by neither economic depression nor economic growth. This evidence points to deep-rooted inequality and entrenched social injustice in the UK. 
The results also point to important generational effects: a significant period-cohort interaction for the youngest generation suggests that economic crisis had a particularly strong effect on the internal capabilities of the youngest generation. It is already well established that youth unemployment has a 'scarring' effect on future labour market outcomes (Clark, Georgellis and Sanfey 2001; Gregg 2001). The present study has highlighted the possibility of additional, non-economic scarring effects: those in their formative years during hard times significantly increased their prioritisation of subsistence values; based on the underlying cohort trend the opposite result would be expected for this generation, and the effect is particularly striking when compared to the previous formative generation who developed their goals and life plans during the economic boom. This is highly relevant from a capabilities point of view for both individuals and the social collective. The life goals and plans developed during this life-stage are formative in terms of the life trajectories and future well-being of individuals; constrained internal capability at this stage is likely to be associated with diminished freedom to achieve well-being in the future. There are also implications for the mass priorities of society and the character of future social institutions, as this cohort enters public life and goes on to take up positions of power (Mannheim 1952). The analysis shows that the formative cohort placed significantly more importance on stability, social order and conventional norms, and less importance on creativity, innovation and adventure; it is possible that this could have a detrimental effect on future capability space and social progress at the national level:

...modernization's changes are not irreversible. Economic collapse can reverse them, as happened during the Great Depression in Germany, Italy, Japan, and Spain...

(Inglehart and Welzel 2010)

\section{Dynamic capabilities}

The analysis here confirms previous findings that adaptation to deprivation ought to be a consideration for the CA: the problems of "compensating abilities" (Qizilbash 1997) and conditioned agency goals (Burchardt 2009) suggest that inter-personal evaluations of well-being in the capability space are problematic if they are based on (1) present equality of capability or (2) achievement of agency goals. Burchardt and Qizilbash suggest similar solutions to the problems they identify. First, both advocate a move away from a static view of capability to a dynamic view, through the inclusion of inter-temporal dimensions of capability. Since equality of capability at a single time-point is compatible with injustice, capability at earlier life stages should be included in evaluations: the woman who has developed compensating abilities may then be shown to have suffered from unequal capability over the course of her life (Qizilbash 1997). Similarly, to evaluate real freedom, it is necessary to evaluate not only the capability set within which agency goals are pursued, but also the capability set within which they were formed (Burchardt 2009). The importance highlighted here of the dynamic aspects of capability reflects the more general insight that people do not have a single set of unchanging goals (Elster 1982); through processes of practical reasoning, people are constantly adapting and adjusting in response to changes in their life-worlds. The important issue for evaluations of well-being is the nature of the adaptation and the reasons behind it. 
A second possible solution to the problem of adjustment to deprivation is the inclusion of goals and aspirations in the definition of capability, as internal (subjective) constraints, such that lower aspirations equate to lower capability (Burchardt 2009; Qizilbash 1997). Burchardt dismisses this solution on the basis that the inclusion of aspirations and goals in the definition of what limits a capability set may open the door to the inclusion of innumerable mental states and dispositions; this could be overly deterministic, and in the end may reduce the analytical traction of the concept of capability.

However, Nussbaum's (2000) distinction between basic, internal and combined capabilities provides a basis for the legitimate and useful conceptualisation of aspirations and expectations as subjective constraints on capability. The concept of internal capabilities, and the distinction between these and combined capabilities, provides a solid foundation for the inclusion of aspirations and expectations as a dimension of internal capability: it seems clear that what a person is free to imagine for themselves - the boundaries of their practical reasoning - constitutes a constraint on what they are substantively free to achieve:

If I have never seen or heard a piano, I am unlikely to form the goal of becoming a concert pianist...if no-one in my family has ever been to university, it is much less likely (although of course not impossible), that I will set myself the objective of obtaining a degree. (Burchardt 2009)

The conceptualisation of aspirations as a dimension of internal capability satisfies the requirement of including information beyond the achievement of agency goals in evaluations of well-being; it is compatible with a dynamic perspective on capabilities; and it captures the intuition that one is not realistically free to achieve that which lies beyond one's horizon of imagined possibility.

\section{Conclusion}

An important critique of the capabilities approach is that it is subject to an analogous problem of adaptation to deprivation as subjective approaches to well-being. This paper has examined the effects of economic crisis on practical reasoning and conceptions of value in the UK. The analysis has provided evidence that hard economic times did enter into people's practical reasoning about what constitutes a good life: during hard times there was widespread re-specification of ends in accordance with subsistence goals such as security, stability and certainty, with effects concentrated among those living in low-income households, and the formative generation. This adaptation represents a move away from higher human potential goals, and a diminishment of internal capability. The combination of constrained external circumstances and diminished internal capability amounts to a double setback for the combined capabilities of these groups.

There are several implications for policy. The findings highlight unequal vulnerability among different sections of society: Among vulnerable groups lacking in socio-economic buffers, the shock of the economic crisis was absorbed through a downgrading of goals and aspirations. The evidence of this type of adaptation reinforces the need for policies that, during good times, work to remove 
structural socio-economic inequalities and precarity and, during hard times, focus efforts on building and maintaining the combined capabilities of the economically vulnerable, in terms of both reducing objective material insecurity, and expanding subjective horizons of possibility and opportunity. The evidence also suggests that tailored interventions are needed to address the precarious situation of those who fall just above the official low-income threshold. With regard to the youngest generation, the findings suggest that, in future hard times, the internal capabilities of young people should be high on the policy agenda, and measures should be taken to support the formative generation in maintaining aspirations and expectations, for example through investment in skills and education, and a special focus on opportunities for employment and volunteering for the young. A capabilities perspective has provided important additional insight into why such policies are important, and how efforts should be focused.

Finally, there are important implications for the capabilities approach more generally. The evidence confirms that practical reasoning is sensitive to changing external circumstances, and that conceptions of value are adaptive. This finding adds further support to calls for a dynamic view of capabilities; I have suggested that this can be achieved through the inclusion of goals, aspirations and expectations as a dimension of internal capability. A person's conception of the good functions as a subjective constraint on what she is free to imagine as substantively possible for herself; a respecification of ends in accordance with subsistence needs amounts to a narrowing of horizons and a downgrading of goals - in short, a diminishment of internal capability, and therefore a shrinkage of her combined capability set.

In conclusion, this paper has shown that the evaluation of people's freedom to live flourishing human lives requires a dynamic perspective on capabilities that takes into account the endogenous dynamics of - and external influences on - practical reasoning. This dynamic perspective is in line with Aristotle's definition of well-being as not a state, but an active process. Most importantly, while the problem of adaptive preferences is a fatal flaw in utilitarian-monist accounts of well-being, the inclusion of subjective conceptions of value is perfectly compatible with the multi-dimensional, pluralist account of well-being at the heart of the CA. The incorporation of conceptions of value foregrounds the issue of adaptation to deprivation, and this has the potential to enhance the power of the capabilities approach in promoting well-being, and identifying and addressing ill-being, injustice and inequality. 


\section{Notes}

1. A classical scale approach was used to measure the eight core values, rather than individual confirmatory factor analyses. Although a classical approach introduces the possibility of increased measurement error, it allows the grand-mean centering of the survey items; this approach to operationalising the eight values was therefore judged to better express the idea of differential prioritisation of personal values.

2. Measurement invariance at four levels - configural, weak, strong and strict - was tested using a multiple-group extension of the exploratory factor measurement model, and the results confirmed that meaningful comparisons can legitimately be made across the two time periods of interest. Details available on request.

3. Any analysis that examines change over time or investigates the effects of time-specific phenomena (e.g. an economic crisis) must take into account distinct possible sources of change, namely Age, Period, and Cohort effects. These are exactly collinear with each other (each is a linear function of the other two), and so all three cannot be directly entered into a single equation. A workaround found in the literature is to use "social ageing" or "lifecycle characteristic" variables as proxies for age (e.g. Ford 2008).

4. The education reference category is A-level and above: although "A-level" is distinguished from "Degree and higher" in the survey, multicollinearity diagnostics suggested that a single "higher education" category was optimal.

5. Household income categories were calculated with reference to the median household income for each year of the survey, using data from the Office for National Statistics (Household Income and Expenditure Table 14: Average Incomes, Taxes and benefits by decile groups of all households, 19772012/13). Categories are based on unequivalised data, and income is assumed to be uniformly distributed within categories.

6. It is notable that, despite being markers of economic vulnerability, unemployment and long-term sickness/disability are not associated with a prioritisation of subsistence values. More detailed research about the value priorities associated unemployment and long-term illness would be useful.

7. Limitations and future research: The principal limitation of this analysis was the trade-off between survey design and content: as noted in Section 2, due to the absence of suitable longitudinal data on value priorities in the UK, the analysis was limited to comparing equivalent groups across time periods. Future research that took a longitudinal perspective would enable analysis of the longerterm consequences of economic crisis for combined capabilities and achieved functioning, for different sections of society. In addition, future research could use more sensitive indicators of income poverty, for example, hybrid approaches that combine relative and absolute indicators, and take direct account of the different resources requirements of different sized households. Another promising avenue of future research would be to extend this work cross-nationally, using a comparative case-study approach or a multi-level quantitative analysis, in order to examine questions about context effects, including, for example, the role played by different institutional environments and policy responses to hard times. 


\section{References}

Allport, G.W. 1961. Pattern and Growth in Personality. New York: Holt, Rinehart and Winston.

Anand, P, J Krishnakumar, and NB Tran. 2011. "Measuring Welfare: Latent Variable Models for Happiness and Capabilities in the presence of Unobservable Heterogeneity." Journal of Public Economics 95(3-4):205-215.

Aristotle. 1976. The Ethics of Aristotle: Nichomachean Ethics. London: Penguin Classics. Translated by J.A.K. Thomson.

Asparouhov, T, and B Muthen. 2009. "Exploratory Structural Equation Modeling." Structural Equation Modeling-a Multidisciplinary Journal 16(3):397-438.

Brandtstadter, J, and G Renner. 1990. "Tenacious Goal Pursuit and Flexible Goal Adjustment Explication and Age-related Analysis of Assimilative and Accommodative Strategies of Coping." Psychology and Aging 5(1):58-67.

Burchardt, T. 2009. "Agency Goals, Adaptation and Capability Sets." Journal of Human Development and Capabilities 10(1):3-19.

Camfield, L, K Choudhury, and J Devine. 2009. "Well-being, Happiness and Why Relationships Matter: Evidence from Bangladesh." Journal of Happiness Studies:71-91.

Clark, A., Y. Georgellis, and P. Sanfey. 2001. "Scarring: The Psychological Impact of Past Unemployment." Economicia 68(270):221-41.

Clawson, C. J., and D.E. Vinson. 1978. "Human Values: a Historical and Interdisciplinary Analysis." Advances in Consumer Research 5(1):396-402.

Dancy, J. 2000. "Practical Reality." Oxford: Clarendon Press.

Davidov, E, P Schmidt, and SH Schwartz. 2008. "Bringing Values Back In - The Adequacy of the European Social Survey to Measure Values in 20 Countries." Public Opinion Quarterly 72(3):420-445.

Doyal, L, and I Gough. 1991. A Theory of Human Need. Basingstoke: Macmillan.

DWP. 2013. "Information on the Standard of Living of the Household Population in the UK" Department for Work and Pensions, 14 June 2013, https://www.gov.uk/government/collections/households-below-average-income-hbai--2.

Elster, J. 1982. " Sour Grapes - Utilitarianism and the Genesis of Wants." in Utilitarianism and beyond, edited by A. Sen and B. Williams. Cambridge: Cambridge university Press.

Emmel, N, and K Hughes. 2010. "Recession, it's all the same to us son': The Longitudinal Experience (1999-2010) of Deprivation." Twenty-First Century Society: Journal of the Academy of Social Sciences, Special Issue: Lived experience through economic downturn in Britain 5(2).

European Social Survey. 2014. http://www.europeansocialsurvey.org/data/themes.html?t=values. Festinger, L. 1954. "A Theory of Social Comparison Processes." Human Relations 7:117-140. Ford, R. 2008 "Is Racial Prejudice Declining in Britain?", British Journal of Sociology 59(4): 609-636. Gregg, P. 2001. "The Impact of Youth Unemployment on Adult Unemployment in the NCDS." The Economic Journal 111(475):626-53.

Hitlin, S., and J. A. Piliavin. 2004. "Values: Reviving a Dormant Concept." Annual Review of Sociology 30:359-393.

Inglehart, R. 1977. The Silent Revolution: Changing Values and Political Styles among Western Publics. Princeton: Princeton University Press.

Inglehart, R, and C Welzel. 2010. "Changing Mass Priorities: The Link between Modernization and Democracy." Perspectives on Politics:551-567.

Ipsos-Mori. 2012. "Generations." www.ipsos-mori-generations.com.

Kluckhohn, C.K.M. 1951. "Values and Values Orientations in the Theory of Action." Pp. 388-433 in Toward a general theory of action, edited by T Parsons and E Sils. Cambridge, MA: Harvard University Press.

Korsgaard, C. 2009. Self-constitution: Agency, Identity, and Integrity: Oxford University Press.

Krishnakumar, J, and P Ballon. 2008. "Estimating Basic Capabilities: A Structural Equation Model applied to Bolivia." World Development 36(6):992-1010. 
Kuklys, W. 2005. "The Measurement of Functionings Achievement: Structural Equation Models as an Alternative." in Amartya Sen's Capability Approach: Theoretical insights and empirical applications. Berlin: Springer.

Mannheim, Karl. 1952. "The Problem of Generations." in Essays on the Sociology of Knowledge, edited by Paul Kecskemeti. London: Routledge \& Kegan Paul (first published 1923).

Marsh, H., Liem, G., Martin, A., Nagengast, B. and Morin, A. 2011 "Methodological Measurement Fruitfulness of Exploratory Structural Equation Modeling (ESEM): New Approaches to Key Substantive Issues in Motivation and Engagement." Journal of Psychoeducational Assessment 29(5): 497-497.

Maslow, AH. 1943. "A Theory of Human Motivation." Psychological Review 50:370-396.

Mill, J.S. 1998/1871. Utilitarianism. Oxford: Oxford University Press.

Nussbaum, MC. 2000. Women and Human Development: the Capabilities Approach: Cambridge University Press.

ONS. 2012. "Labour Market Statistics, June 2012." London: Office for National Statistics.

Qizilbash, M. 1997. "A Weakness of the Capabilities Approach with respect to Gender Justice." Journal of International Development 9:251-263.

Rohan, MJ. 2000. "A Rose by any Name? The Values Construct." Personality and Social Psychology Review:255-277.

Rokeach, Milton. 1973. The Nature of Human Values. New York: The Free Press.

Sayer, Andrew. 2011. Why Things Matter to People: Social Science, Values and Ethical Life: Cambridge University Press.

Schwartz, SH. 1992. "Universals in the Content and Structure of Values - Theoretical Advances and Empirical Tests in 20 Countries." Advances in Experimental Social Psychology:1-65.

Schwartz, SH. 2003. "A Proposal for Measuring Value Orientations Across Nations." ESS Questionnaire Development Report: 259-319.

Sen, A. 1985a. Commodities and Capabilities. Amsterdam: North Holland.

Sen, A. 1985b. "Freedom and Agency." Journal of Philosophy 82(4):203-221.

Sen, A. 1992. Inequality reexamined. Cambridge, MA: Harvard University Press.

Sen, A. 1999. Development as Freedom. Oxford: Oxford University Press.

Slay, J., and J. Penny. 2013. "Surviving Austerity: Local Voices and Local Action in England's Poorest Neighbourhoods." London: New Economics Foundation. NEF 2013.

Smith, M. 1994. The Moral Problem. Oxford: Blackwell.

Steiner, H. 1994. An Essay on Rights. Oxford: Blackwell.

Teschl, M., and F Comim. 2005. "Adaptive Preferences and Capabilities: Some Preliminary Conceptual Explorations." Review of Social Economy LXIII(2):230-246.

Wiggins, D. 2001. "Deliberation and Practical Reason." in Varieties of Practical Reason, edited by E. Millgram. Cambridge, MA: MIT Press.

World Bank. 2013. "National Accounts Data." in World Development Indicators. Washington DC http://data.worldbank.org/indicator/NY.GDP.MKTP.KD.ZG?page=1. 